\title{
GENETIC EROSION IN THE FRESHWATER SNAIL FILOPALUDINA MARTENSI IS AFFECTED BY LEAD AND CADMIUM
}

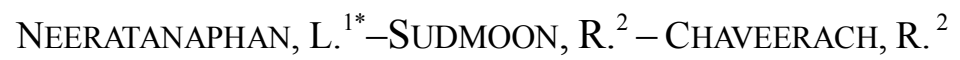 \\ ${ }^{I}$ Department of Environmental Science, Faculty of Science, Khon Kaen University, \\ Khon Kaen 40002, Thailand \\ ${ }^{2}$ Department of Biology, Faculty of Science, Khon Kaen University, Khon Kaen \\ 40002, Thailand \\ *Corresponding author \\ e-mail:hlamya@kku.ac.th \\ (Received $24^{\text {th }}$ Jan 2013; accepted $22^{\text {nd }}$ July 2014)
}

\begin{abstract}
This study aims to determine the lead $(\mathrm{Pb})$ and cadmium $(\mathrm{Cd})$ concentrations and genetic variability in the tissues of the freshwater snail Filopaludina martensi. These measures can be biomarkers of environmental quality. The samples were collected over three seasons from five sites around the Ubonrat $\mathrm{Dam}$. The results showed that the average concentrations of $\mathrm{Cd}$ and $\mathrm{Pb}$ found in the tissue of fresh water snails during the rainy season $(0.1040$ and $0.0106 \mu \mathrm{g} / \mathrm{g}$, respectively) were higher than in the winter $(0.0566$ and 0.0030 , respectively) and summer $(0.0654$ and $0.0059 \mu \mathrm{g} / \mathrm{g}$, respectively). Random amplified polymorphic DNA (RAPD) was successfully applied to produce 440 total bands used for dendrogram construction and analysis of genetic similarity (S). The dendrogram separated the studied samples by seasons, showing the highest $\mathrm{S}$ values of $0.59-0.93$ in the Rainy S1-S5 and S2-S3, 0.62-0.83 in the Winter S1-S4 and S1-S2, and 0.64-0.84 in the Summer S1-S5 and S2-S3. The highest S values in the rainy season that are lower values compare to samples from other seasons are those associated with the highest average concentrations of $\mathrm{Cd}$ and $\mathrm{Pb}$ in the tissues sampled in this season. The metal concentrations are below the standard control level, but they can still affect the genetic material of freshwater snails.
\end{abstract}

Keywords: Lead, cadmium, freshwater snail, genotoxicity, genetic erosion

\section{Introduction}

Heavy metals are often contaminants in marine and freshwater environments, where they are generally found in low concentrations. However, human activities have increased the levels of metal ions in many of these natural water systems. Industrial and domestic effluents in particular have contributed to the increased metal loads in coastal waters and are ultimately deposited into aquatic sediments (Ansari et al., 2004; Pandey et al., 2010). These metals accumulate in organisms, and some may become biomagnified in food chains (Singh et al., 2010). Many aquatic organisms uptake metals directly from the water, so tissue concentrations reflect metal concentrations in the water. Carnivores at the top of the food chain, such as aquatic birds and mammals (including humans), however, obtain most of their pollutant burden from aquatic ecosystems by ingestion, especially of fish, which have a considerable potential for biomagnification (Richter and Nagel, 2006).

The determination of total heavy metal contents in sediments has not been performed up to now because the behavior of heavy metals is closely related to their chemical forms, and only those with high bioavailability can be absorbed by organisms and do great harm to other organisms and human beings. Thus, the investigation of heavy metal

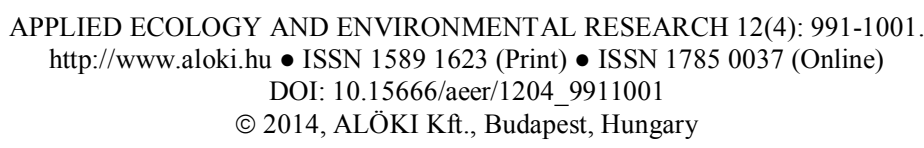


contamination in organisms more directly reflects the hazards to human health and the potential heavy metal pollution in water. Lying in the second trophic level in the water ecosystem, mollusks have long been known to accumulate both essential and non-essential trace elements from aquatic ecosystems (Liang et al., 2004; Wagner and Boman, 2004; Norum et al., 2005). Mollusks, including freshwater snails and bivalves, have long been regarded as promising bio-indicators and bio-monitoring subjects. They are abundant in many terrestrial and aquatic systems, making them easily available for collection. They are highly tolerant to many pollutants and exhibit high accumulation properties, particularly for heavy metals. Mollusks living in the sea can accumulate heavy metals and may serve as excellent passive bio-monitors (Wang et al., 2005).

The Pong River is the principle river in Northeastern Thailand. The Moon River is the continuation of this waterway into the lower northwest of this region, thus any water pollution would have a combined effect. People living in the Loei province, the Nongbualamphu province and the Khonkaen province utilize these rivers for consumption and agriculture. Despite reports of water pollution in the Pong River since 1986, there has still been a continuing crisis of water pollution as reported in 1992 (Faculty of Engineering, 2003). Sources of pollution came from several industries, and noted a high impact on the Pong River. Examples of these industries include a paper mill factory, a combined gas turbine power plant, a distillery plant, a sugar factory and wood working plants. In addition, there are several smaller industries located within the vicinity of the Pong River. These are all likely major causes of heavy metal contamination in the Pong River along with traces from pesticides, chemical fertilizers and other wastes from the community.

The genotoxicity measurement process in living tissue at the DNA is advantageous because of its sensitivity and short response time (Gupta and Sarin, 2009). Heavy metals have an acute genotoxic potential in all living things. Immediately releasing these pollutants can cause morbidity and mortality in the exposed organism and can provoke order changes such as alterations to population dynamics and changes in biological diversity (An et al., 2012). Random amplified polymorphic DNA (RAPD) is extremely efficient for DNA analysis in complex genomes as it is simple, inexpensive and minimally time-consuming. The resulting bands can be scored to evaluate genetic similarities and dissimilarities of samples through dendrogram construction. That is, RAPD bands are generally used to effectively indicate genetic relationships. The concept critical to cladistics is homology, which can be defined as a similarity resulting from common ancestry. Therefore, the cladogram designed depicts not only similarity but also evolutionary relatedness (Simpson, 2006).

The freshwater snail Filopaludina martensi Frauenfeld 1865 is a benthic fauna in the food chain ecosystem that lives and moves slowly to feed on the surface of sediments and thus accumulates heavy metals. This study aims to determine heavy metal accumulation in fresh water snail tissue and the genetic relationship shown by the similarity index, assessing other toxic contaminants through RAPD analysis.

\section{Materials and methods}

\section{Sampling sites}

The Pong River is the principle river in Northeastern Thailand, and the Moon River is the continuation of this waterway into the lower part of this region. These rivers support agricultural farms and many industries. The Bueng Jode reservoir receives a

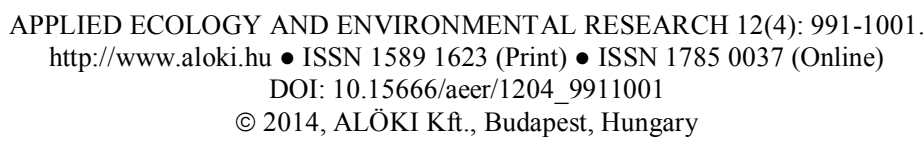


considerable amount of effluents from a paper mill factory before flowing into the Pong River. Five sampling sites were defined as the affected area of the Pong River (Fig. 1).

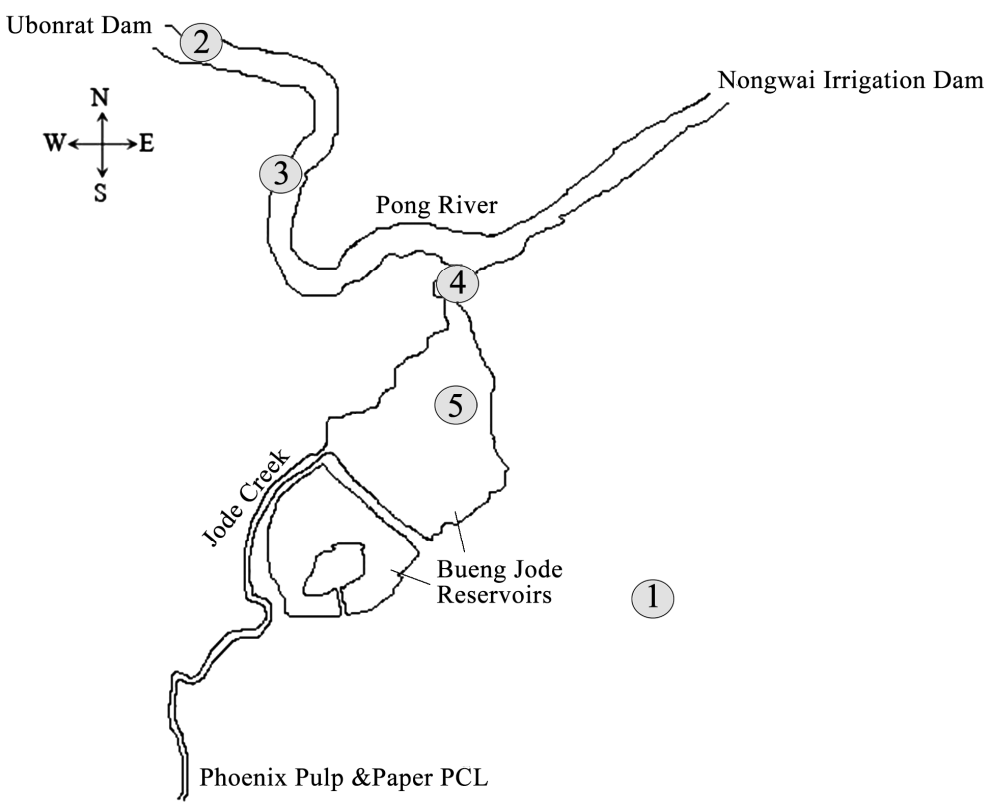

Figure 1. Overview of the Pong River and locations of the five sampling sites as shown by numbers 1 to 5

\section{Sampling and sample analysis}

Freshwater snails were collected from the five sites in three consecutive seasons in 2010. The concentrations of $\mathrm{Cd}$ and $\mathrm{Pb}$ were evaluated following these steps:

Three samples from each sampling site were homogenized, the soft tissues of freshwater snails were excised using a sterile stainless steel scalpel. These tissues were predigested with $3 \mathrm{ml}$ of concentrated nitric acid overnight at $40^{\circ} \mathrm{C}$. After cooling, $2 \mathrm{ml}$ of $30 \%$ hydrogen peroxide was added. There after the container was covered and placed in a high-pressure stainless steel bomb then put in an oven. The oven temperature was increased to $160^{\circ} \mathrm{C}$ and kept for $4 \mathrm{hrs}$. After cooling, the solution was diluted with Milli$\mathrm{Q}$ water and transferred into a PET bottle to $50 \mathrm{~g}$. $\mathrm{Cd}$ and $\mathrm{Pb}$ concentrations were determined with inductively coupled plasma-optical emission spectrometry (ICP-OES), PerkinElmer (Optima $4300 \mathrm{AV}$ ). For the wavelength analysis of ICP, wavelengths of Cd and $\mathrm{Pb}$ were 228.802 and $220.353 \mathrm{~nm}$, respectively. The results are reported as dry weight. The accuracy of the results for heavy metal was evaluated with the certified reference material (CRM) using the 3111C method (APHA, 2005). Two aliquots of the CRM were spiked with a known amount of heavy metal spike standard, and one spike was analyzed according to $3111 \mathrm{C}$ method while the other was analyzed with the $3111 \mathrm{~B}$ method (APHA, 2005). The metal recoveries were in the 96-100\% range, which was acceptable (USEPA, 1994). 


\section{Statistical analysis}

The seasonal variations and sampling sites were analyzed using SPSS V.19. All the statistical tests were conducted at a 95\% confidence level. The data normality was tested using the Kruskal-Wallis test.

\section{DNA extraction}

DNA was extracted from kidney tissue using the Genomic DNA Extraction Kit (RBC Bioscience, Taiwan) following the manufacturer's instructions. The extracted DNA was checked by $0.8 \%$ agarose gel electrophoresis and then diluted to a final concentration of $20 \mathrm{ng} / \mu \mathrm{l}$.

\section{DNA fingerprinting and analysis by $R A P D$ marker}

Amplifications were carried out on each sample in $25 \mu \mathrm{l}$ reactions consisting of GoTaq Green Master Mix (Promega), $0.5 \mu \mathrm{M}$ primer and $5 \mathrm{ng}$ DNA template. Several RAPD primers were screened and the 12 primers that successfully amplified clear bands are as follows $\left(5^{\prime}\right.$ to $\left.3^{\prime}\right)$ : CATCCCCCTG, GGACCCTTAC, GTCCCGACGA, AAGCCTCGTC, CAGGCCCTTC, TGCCGAGCTG, AATCGGGCTG, GGGTAACGCC, CAATCGCCGT, CAAACGTCGG, GACCTACCAC and TCAGTCCGGG. The reaction mixture was incubated at $94{ }^{\circ} \mathrm{C}$ for $3 \mathrm{~min}$ and the amplification was performed with the following thermal cycles: 35 cycles of denaturation for $1 \mathrm{~min}$ at $94{ }^{\circ} \mathrm{C}, 2 \mathrm{~min}$ annealing temperature at $40{ }^{\circ} \mathrm{C}, 2 \mathrm{~min}$ at $72{ }^{\circ} \mathrm{C}$, and $7 \mathrm{~min}$ final extension at $72{ }^{\circ} \mathrm{C}$ using a thermal cycler (Swift ${ }^{\mathrm{TM}}$ Maxi Thermal Cycler, Esco Micro Pte. Ltd.). Amplification products were detected by $1.2 \%$ agarose gel electrophoresis in TAE buffer and visualized using ethidium bromide. The resulting RAPD bands were used for the dendrogram construction.

The RAPD bands from the primers that resulted in successful amplification were discerned on an agarose gel and were documented as diallele characters: present $=1$ and absent $=0$. These resulting bands were used to construct a dendrogram following NTSYSpc 2.10p (Rohlf, 1998). The dendrogram and genetic similarities were produced.

\section{Results and Discussion}

\section{Cd and Pb concentrations}

The $\mathrm{Cd}$ and $\mathrm{Pb}$ concentrations from the tissue of freshwater snail samples are shown in Table 1. The average concentration values of $\mathrm{Cd}$ and $\mathrm{Pb}$ in the winter, summer and rainy seasons are $0.0566,0.0030 ; 0.0654,0.0059$; and $0.1040,0.0106 \mu \mathrm{g} / \mathrm{g}$ of tissue, respectively. The contaminated values are higher in the rainy season than in the winter and summer. Statistical analysis shown in Table 2 indicates that there are no significant differences between study sites or weather seasons with regard to $\mathrm{Cd}$ and $\mathrm{Pb}(p>0.05)$.

\section{DNA fingerprinting of freshwater snail}

The 12 successful RAPD primers generated clear and testable fingerprinting profiles. Examples of fingerprints are shown in Figure 2-4. 
Table 1. Concentrations of $C d$ and $P b$ in freshwater snail tissue $(\mu \mathrm{g} / \mathrm{g}$, dry weight)

\begin{tabular}{lcc}
\hline \multirow{2}{*}{ Parameter } & Cd content & Pb content \\
\cline { 2 - 3 } Winter season & $(\mu \mathrm{g} / \mathrm{g})$ & $(\mu \mathrm{g} / \mathrm{g})$ \\
\hline Site 1 & & \\
Site 2 & 0.0290 & 0.0011 \\
Site 3 & 0.0310 & 0.0009 \\
Site 4 & 0.0390 & 0.0027 \\
Site 5 & 0.1100 & 0.0050 \\
\hline Average & 0.0740 & 0.0053 \\
\hline SD & 0.0566 & 0.0030 \\
\hline Summer season & 0.0349 & 0.0021 \\
\hline Site 1 & & \\
Site 2 & 0.0930 & 0.0073 \\
Site 3 & 0.1100 & 0.0051 \\
Site 4 & 0.0360 & 0.0170 \\
Site 5 & 0.0570 & 0.0000 \\
\hline Average & 0.0310 & 0.0000 \\
\hline SD & 0.0654 & 0.0059 \\
\hline Rainy season & 0.0349 & 0.0070 \\
\hline Site 1 & & \\
Site 2 & 0.0630 & 0.0160 \\
Site 3 & 0.0700 & 0.0210 \\
Site 4 & 0.0340 & 0.0043 \\
Site 5 & 0.3200 & 0.0030 \\
\hline Average & 0.0330 & 0.0086 \\
\hline SD & 0.1040 & 0.0106 \\
\hline & 0.1219 & 0.0077 \\
\hline
\end{tabular}

Table 2. Values obtained from SPSS test

\begin{tabular}{lcr}
\hline Source of variation & $p$ value $(\mathrm{Cd})$ & $p$ value $(\mathrm{Pb})$ \\
\hline Sample sites & 0.393 & 0.792 \\
Seasons & 0.826 & 0.248 \\
\hline
\end{tabular}

Significant value with a confidence level of $95 \%$

Countable bands ranged in size from $100 \mathrm{bp}$ to $2,500 \mathrm{bp}$. Only bands present in at least two of three samples from each studied site in each season were counted. These resulted in 440 total bands, which were used for dendrogram construction. The dendrogram distinguished studied samples into three groups based on the samples from five different sites (S1-S5) and seasonal grouping. 


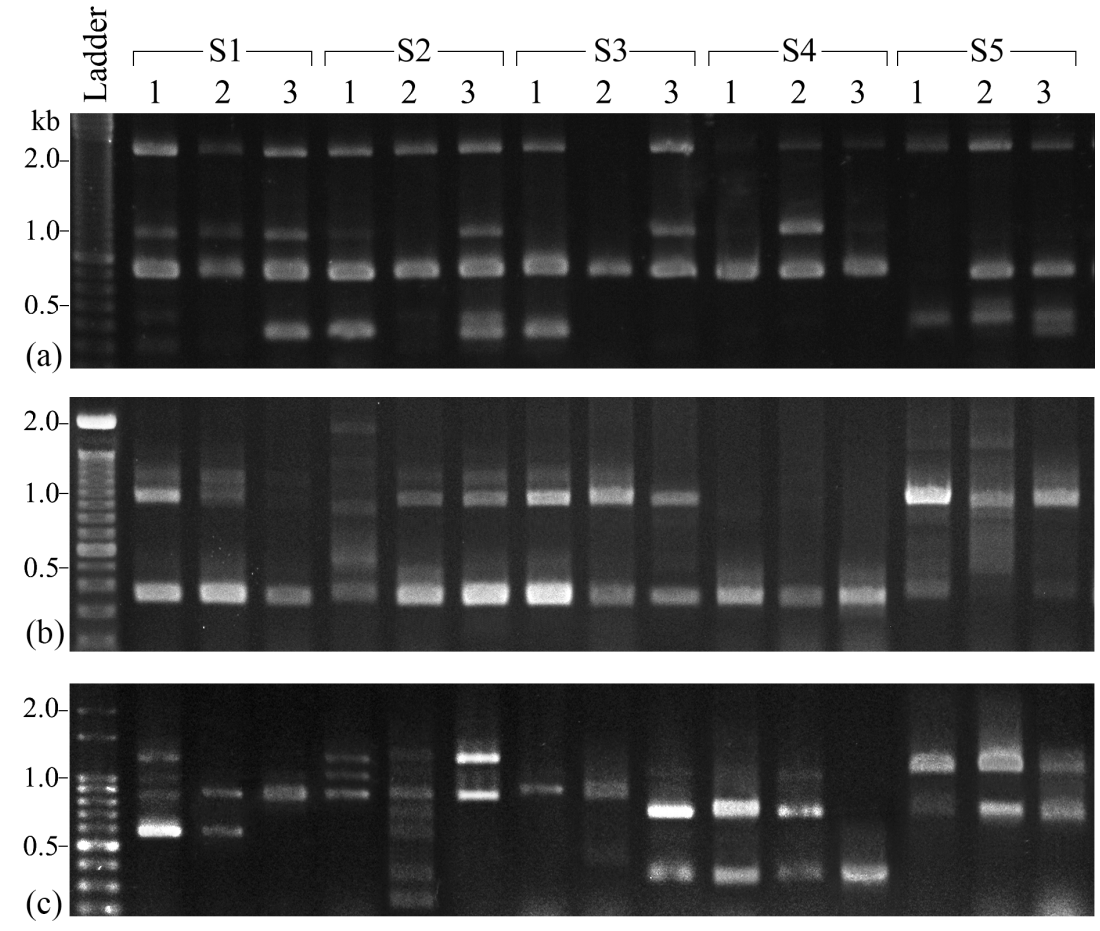

Figure 2. Examples of RAPD fingerprints from all freshwater snail samples studied in the winter from primers CATCCCCCTG (a), CAATCGCCGT (b) and CAAACGTCGG (c)
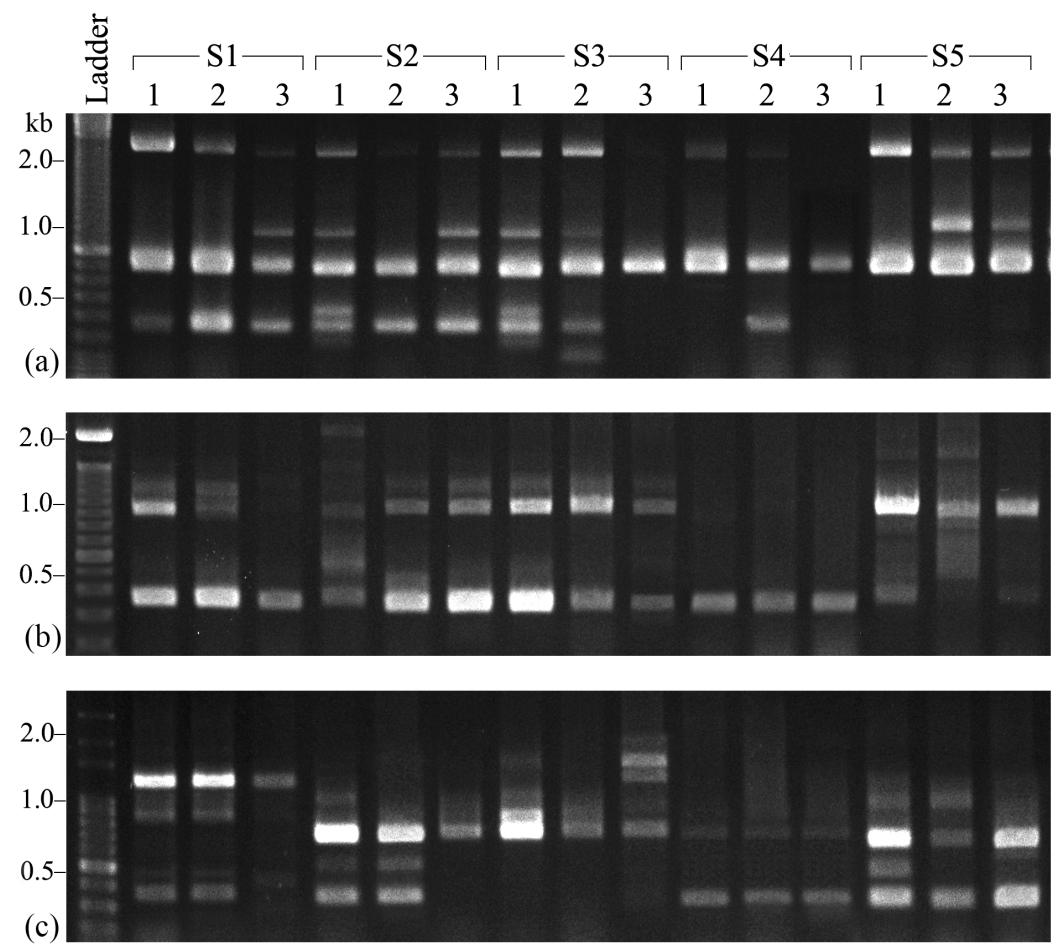

Figure 3. Examples of RAPD fingerprints from all freshwater snail samples studied in the summer from primers CATCCCCCTG (a), CAATCGCCGT (b) and

CAAACGTCGG (c) 


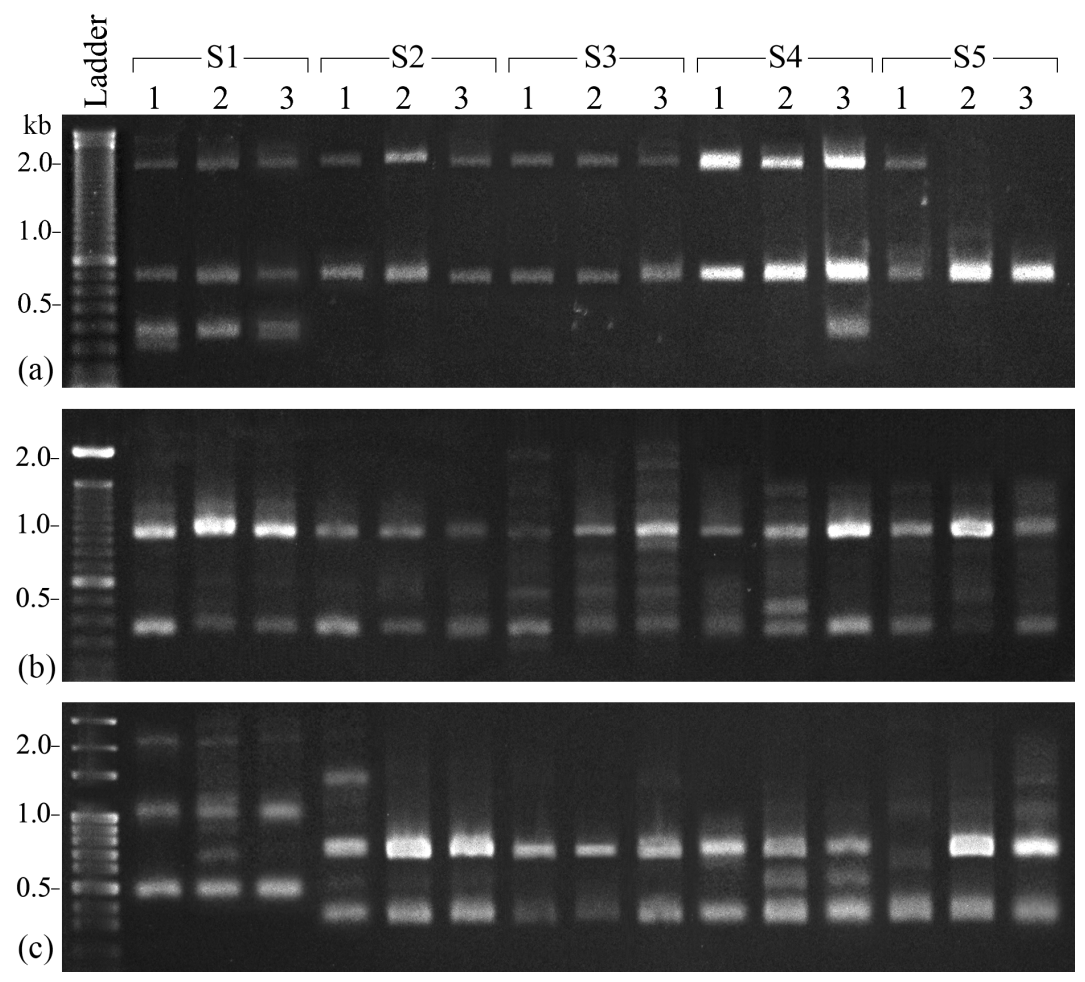

Figure 4. Examples of RAPD fingerprints from all freshwater snail samples studied in the rainy season from primers CATCCCCCTG (a), CAATCGCCGT (b) and CAAACGTCGG (c)

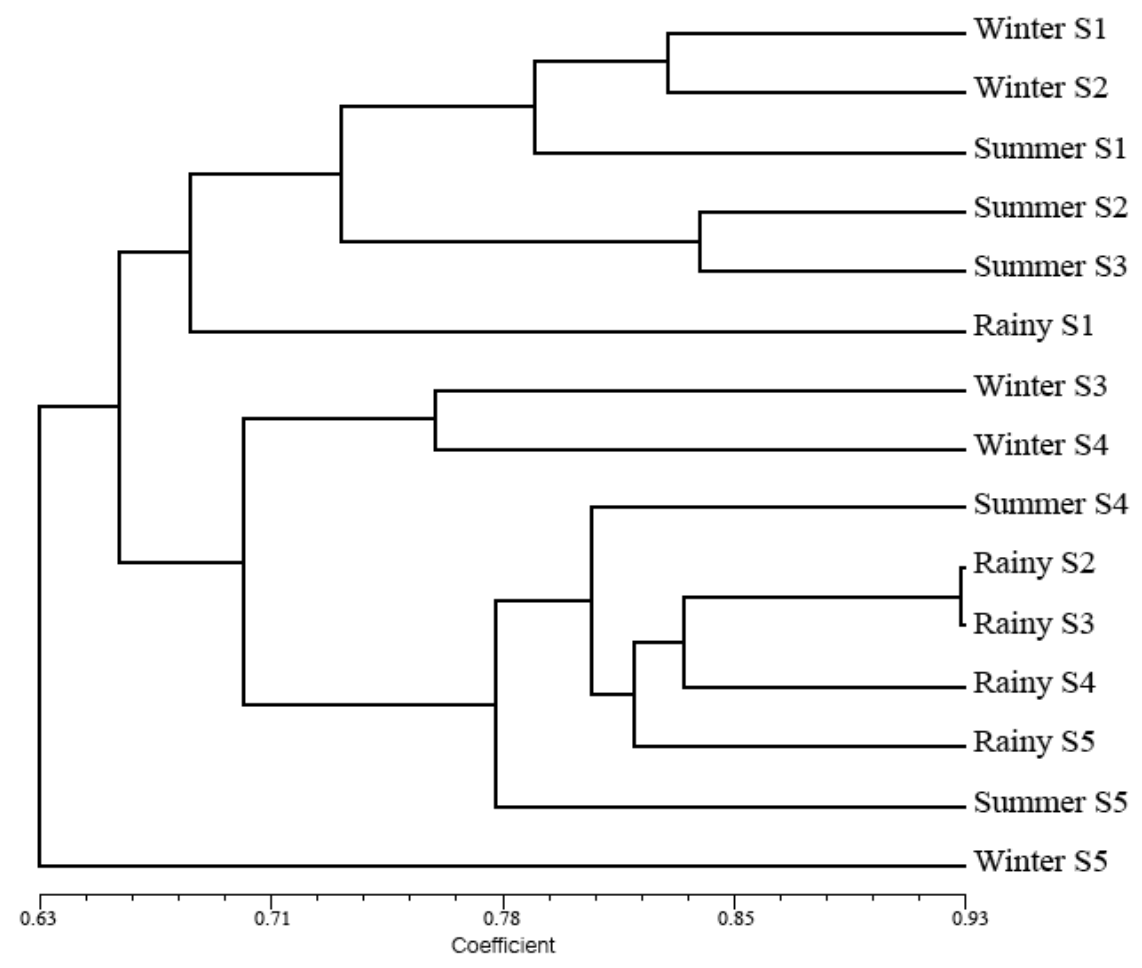

Figure 5. The dendrogram constructed from twelve RAPD primers by the NTSYSpc $2.10 p$ program showing the genetic relationships between the five studied sample sites at different seasons 
Table 3. Relationships of all pairwise studied samples at different seasons indicating genetic similarity values

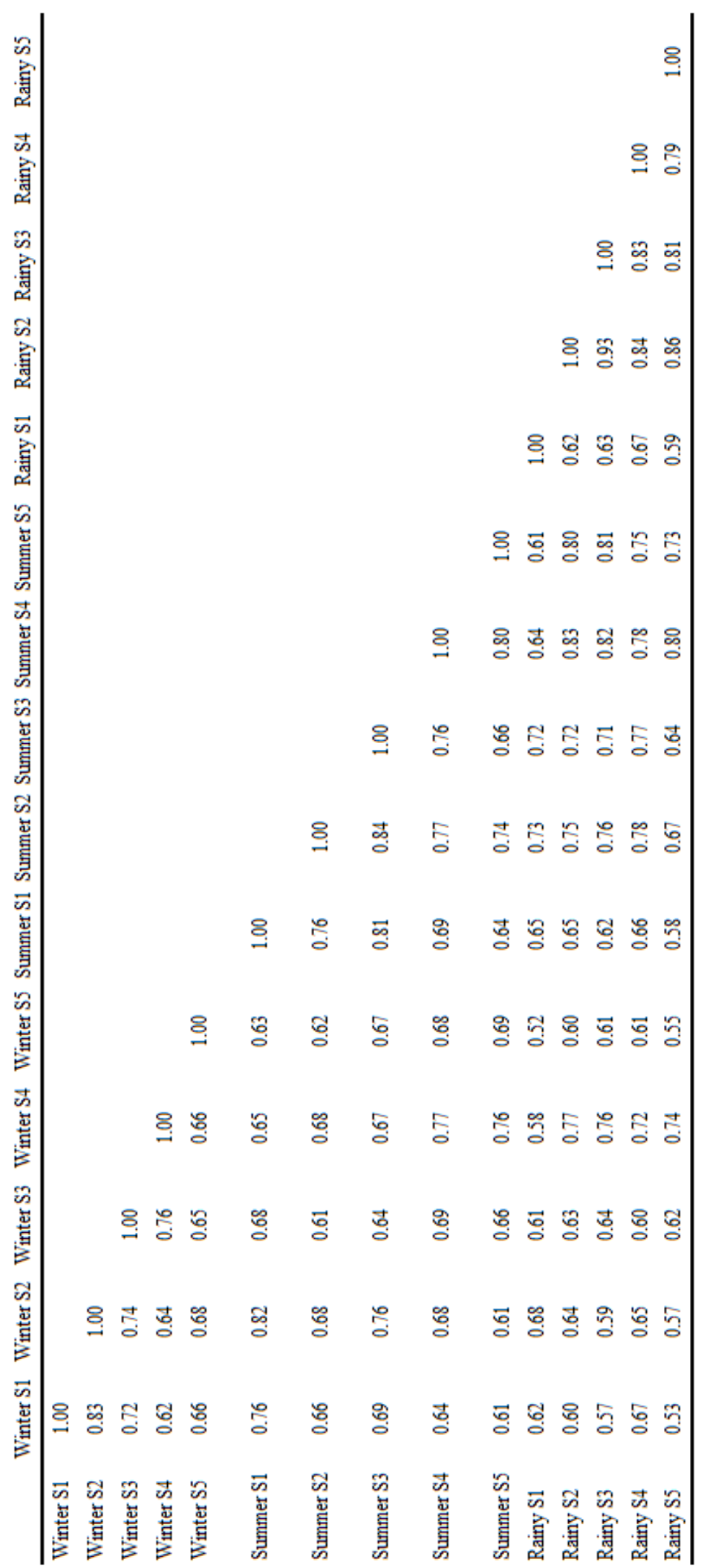


The first group is the Winter S5 only; the second group comprised the Rainy S2, Rainy S3, Rainy S4, Rainy S5, Summer S4, Summer S5, Winter S3 and Winter S4 samples; the third group comprised the Rainy S1, Summer S1, Summer S2, Summer S3, Winter $\mathrm{S} 1$ and Winter S2 samples. The dendrogram (Fig. 5) shows genetic similarity between all studied samples according to the pairwise genetic relationships shown in Table 3. The dendrogram separated the studied samples by seasons and showed the highest $\mathrm{S}$ (0.59-0.93) of the studied samples in the rainy season, Rainy S1-S5 and S2-S3. The other two sites are 0.62-0.83 in the Winter S1-S4 and S1-S2, and 0.64-0.84 in the Summer S1-S5 and S2-S3, respectively.

Toxin-free food is essential for people's wellbeing and animal health. Freshwater snails have long been used as an environmental indicator. However, there are no current studies addressing ecotoxicology of the Pong River or of the potentially harmful impacts of pollutants on food. This research is much needed for supporting agricultural farms and people's life styles in Northeastern Thailand, along with the many industries surrounding them. Consequently, these concerns were addressed in this study by measuring metal concentrations in tissues. The freshwater snail, F. martensi is a muchrelished ingredient in Thailand's cuisine. To ensure quality food and a safe environment around the Pong River, this experiment examined the concentration of heavy metals $\mathrm{Cd}$ and $\mathrm{Pb}$ in the freshwater snail's tissues and determined the cellular biomarker as effective for these objective examinations. The study showed that the average concentrations of $\mathrm{Cd}$ and $\mathrm{Pb}$ found in freshwater snail tissue in the rainy season were 0.1040 and $0.0106 \mu \mathrm{g} / \mathrm{g}$, respectively, and these concentrations are lower in the winter, at 0.0566 and $0.0030 \mu \mathrm{g} / \mathrm{g}$, respectively, and in the summer, at 0.0654 and $0.0059 \mu \mathrm{g} / \mathrm{g}$, respectively. However, there are no significant differences in heavy metal concentrations according to SPSS V.19 analysis (Kruskal-Wallis) for each site $(p=0.393$ for $\mathrm{Cd}, p=0.792$ for $\mathrm{Pb}$ ) or for each season ( $p=0.826$ for $\mathrm{Cd}, p=0.248$ for $\mathrm{Pb}$ ). Accordingly, the dendrogram distinguished the studied samples into the three groups (the Winter S5; the Rainy S2, Rainy S3, Rainy S4, Rainy S5, Summer S4, Summer S5, Winter S3 and Winter S4; the Rainy S1, Summer S1, Summer S2, Summer S3, Winter $\mathrm{S} 1$ and Winter S2) from the different samples from different sites and different seasons, grouping them independently from the heavy metal concentrations. Fortunately, these metal concentration values are below both Thailand's standard control level $(2.0 \mu \mathrm{g} / \mathrm{g}$ (Thailand Pollution Control Department, 1986)) and the Food and Agricultural Organization (FAO) $(2.0 \mu \mathrm{g} / \mathrm{g}$ in $\mathrm{Cd}$ and $1.0-6.0 \mu \mathrm{g} / \mathrm{g}$ in $\mathrm{Pb}$.) The rainy season has running water leaching heavy metals such as $\mathrm{Cd}$ and $\mathrm{Pb}$ from communities and industries into the Pong River, which are then deposited in sediments and accumulate in the tissue of freshwater snails. This likely accounts for the increased concentration of $\mathrm{Cd}$ and $\mathrm{Pb}$ during the rainy season. The freshwater snails in this area are affected by many industries, agricultural fertilizers and insecticides, but can still be of good quality. This animal can endure these two heavy metals, and survive in the environment around the Pong River, which is a moderately contaminated area. This study, in sum, is a field investigation, and there are other possible measures of toxicity from the environment beside these two heavy metals.

Understanding the effect of pollutants on genetic variability is fundamental for preservation. The evolutionary potential of natural populations, the effects of toxic contaminants on the environment, and the effect of $\mathrm{Cd}$ and $\mathrm{Pb}$ on the freshwater snail habitats were investigated at the molecular level using RAPD marker analysis. Genomic DNA modifications such as damage and structure variations were detected, and these 
modifications can be biomarkers. The highest $S$ values $(0.59-0.93)$ in the rainy season samples that were low compared to samples from other seasons are those associated with the highest average concentrations of $\mathrm{Cd}$ and $\mathrm{Pb}$ in the rainy season, suggesting an effect of the metals on the freshwater snail tissue. Although, the heavy metal concentrations are under the standard control level, they can have an effect on the genetic material of the freshwater snail, which is an important ingredient in the local food culture. This study suggests that the freshwater snail is a good indicator species, by which to measure the effectiveness of local waste-water treatment systems.

Note that actual conditions in the field are affected by several pollutants, such as fertilizers, heavy metals, chemicals, and insecticides, etc., in addition to $\mathrm{Cd}$ and $\mathrm{Pb}$, and these pollutants can all have positive and negative effects on the ecosystem.

\section{REFERENCES}

[1] An, L.H., Zheng, B.H., Wang, L.J., Zhang, Y.Q., Chen, H., Zhao, X.R., Zhang, L., Lei, K. (2012): Biomarker responses and genotoxicity in the mud snail (Bullacta exarata) as indicators of coastal contamination. - Mar. Pollut. Bull. 64: 303-309.

[2] Ansari, T., Marr, I., Triq, N. (2004): Heavy metals in environments in marine pollution perspective-a mini review. - J. Appl. Sci. 4: 1-20.

[3] APHA. (2005): Standard methods for the examination of water and wastewater. American Public Health Association, 21 st edition, Washington DC. 2001-3710.

[4] Faculty of Engineering. (2003): Multidisciplinary Study for Integrated Management of the Pong River. - Research progress report for Khon Kaen University.

[5] Gupta, M., Sarin, N.B. (2009): Heavy metal induced DNA changes in aquatic macrophytes: Random amplified polymorphic DNA analysis and identification of sequence characterized amplified region marker. - J. Environ. Sci. 21: 686-690.

[6] Liang, L.N., He, B., Jiang, G.B., Chen, D.Y., Yao, Z.W. (2004): Evaluation of mollusks as biomonitors to investigate heavy metal contaminations along the Chinese Bohai Sea. Sci. Total Environ. 324: 105-113.

[7] Norum, U., Lai, V.W.M., Cullen, W.R. (2005): Trace element distribution during the reproductive cycle of female and male spiny and Pacific scallops, with implications for biomonitoring. - Mar. Pollut. Bull. 50: 175-184.

[8] Pandey, J., Shubhashish, K., Pandey, R. (2010): Heavy metal contamination of Ganga river at Varanasi in relation to atmospheric deposition. - Trop. Ecol. 51: 365-373.

[9] Richter, S., Nagel, R. (2007): Bioconcentration, biomagnification and metabolism of 14C-terbutryn and 14C-benzo[a]pyrene in Gammarus fossarum and Asellus aquaticus. - Chemosphere 66: 603-610.

[10] Rohlf, F. J. (1998): NTSYS_pc: Numerical Taxonomy and Multivariate Analysis System, Version 2.1. - Applied Biostatistics, New York.

[11] Simpson, M.G. (2006): Plant Systematics. - Elsevier Academic Press, California.

[12] Singh, A., Sharma, R.K., Agrawal, M., Marshall, F.M. (2010): Risk assessment of heavy metal toxicity through contaminated vegetables from wastewater irrigated area of Varanasi, India. - Trop. Ecol. 51: 375-387.

[13] Thailand Pollution Control Department (TPCD). (1986): The Standard Levels of Heavy Metals in Tissues of Aquatic Animals. - Notification in Ministry of Public Health No. 98, Bangkok.

[14] U.S. Environmental Protection Agency. (1994): Sample Preparation Procedure for Spectrochemical Determination of Total Recoverable Element, Method 200.2. - Environmental Monitoring Systems Lab, Cincinnati, Ohio.

[15] Wagner, A., Boman, J. (2004): Biomonitoring of trace elements in Vietnamese freshwater mussels. - Spectrochim. Acta Part B. 59: 1125- 1132. 
[16] Wang, Y., Liang, L., Shi, J., Jiang, G. (2005): Study on the contamination of heavy metals and their correlation in mollusk collected from coastal sites along Chinese Bohai Sea. - Environ. Int. 31: 1103-1113. 